\title{
Talent Migration in Knowledge Economy: The Case of China's Silicon Valley, Shenzhen
}

\author{
Grace Yuehan Wang ${ }^{1}$
}

Accepted: 3 July 2021 / Published online: 30 July 2021

(C) The Author(s), under exclusive licence to Springer Nature B.V. 2021

\begin{abstract}
Talent is a key resource in a knowledge economy. It plays a critical role in national economic growth and technological innovation. China's technological power is rising, and its ambitious push for talent is supported by central and local government. Through the lens of Shenzhen, China's Silicon Valley, this article examines the Shenzhen Talent Policy and its effectiveness in attracting both domestic talent and overseas returnees. Document analysis is combined with in-depth interviews with returnee entrepreneurs, university professors, and Shenzhen local government officials to examine talent migration and the effectiveness of talent policy. This study findings reveal that the welcoming and tolerant culture of Shenzhen is key to the city's attractiveness to its existing and potential talent. Entrepreneurial scientists and engineers are likely to return to Shenzhen from abroad for business opportunities in applied innovation and technology commercialization. Academics report an average or dissatisfying attitude towards the scientific environment and professional development. State-led talent policy puts emphasis on technical human capital to meet its urgent developmental needs. The reform of higher education system in Shenzhen is needed to fully realize its technological ambition. In addition, this study shows that younger generation Chinese cares about their personal wellbeing, individual happiness, and career opportunities compared to older generation's emphasis on economic benefits. This article concludes with policy implications on worldwide talent attraction and talent migration in a new geopolitical era.
\end{abstract}

Keywords Shenzhen · China's Silicon Valley · Talent policy · Brain circulation · Returnee entrepreneurs · Migration · Innovation

Grace Yuehan Wang

graceyuehanwang@gmail.com

1 DSI-NRf Centre of Excellence in Scientometrics and STI Policy, CREST, Stellenbosch University, Cape Town, South Africa 


\section{Introduction}

In 1978, China launched the Open and Reform Policy to advance its economic modernization. At the same time, China renewed its national policy of sending students and scholars overseas. Deng Xiaoping, the often called "China's Economic Master," wanted China to catch up with the developed countries in the West and to learn from their advanced technologies and management methods. In Deng's famous speech, Emancipate the mind, Seek truth from facts, Unite and Look forward, he emphasized the importance of economic development with the Chinese characteristics which sent out a clear economic development message: We must learn to manage the economy following the economic and scientific methods. If we do not understand it (i.e., advanced method in managing economy), we should learn from people who know it, and learn from advanced foreign management methods. Not only are newly introduced enterprises to be run in advanced methods, the transformation of the existing enterprises must follow the advanced methods. ${ }^{1}$ Chinese nationals who went to study abroad were expected to return to China with new information, technologies, and management methods. In 1992, during Deng Xiaoping's southern trip to Shenzhen, he emphasized that the Chinese government did not care about overseas students' political attitudes at the 1989 Tiananmen incident. He ensured that all those people could return, and they would be taken care of (Zweig et al., 2004).

More than 40 years have passed since 1978. Talent is as central to China's development as it was four decades ago, if not more urgent. President Xi Jinping has repeatedly addressed the significant role talent plays in advancing Chinese economic development and technological innovation. He called talent "the first resource" in China's "independent innovation" (Zwetsloot, 2020). However, talent alone cannot lead to such innovation or make up for other shortcomings China currently has. China's education system has faced criticism for a long time, particularly for its lack of creativity, its bureaucratic promotion system, its corrupt research grant approval, and its pragmatic academic curriculum. China is aware of its current disadvantages in education and as a result works both to lure quality human capital from abroad to better reform its higher education system and, at the same time, accelerate the training of domestic talent in Science, Technology, Mathematics, and Engineering. China's ambition to become a global technological power is clear (Wübbeke et al., 2016). International responses to China's ambitious talent push and technological expansion are mixed. On one hand, foreign universities, research institutions, and businesses benefit from international talent, and China is the biggest provider. On the other hand, growing concerns about Chinese technology transfer and related talent policies are becoming ferocious (Zwetsloot, 2020).

\footnotetext{
${ }^{1}$ Speech by Deng Xiaoping at the closing ceremony of the Work Conference of the CCP Central Committee on December 13, 1978. The original Chinese translation of his speech is named: 解放思想, 实事 求是, 团结一致向前看。

${ }^{2}$ There are different interpretations of China's “自主创新." Some use “independent innovation" or "indigenous innovation" while others argue "self-directed innovation" is more accurate. In this paper, I adopted the phrase "independent innovation".
} 
Shenzhen, China's Silicon Valley, is at the heart of the global technological competition. According to the World Intellectual Property Organization, in 2017, China filed almost 50,000 international patents, nearly half of them were from Shenzhen. In addition, Shenzhen is home to Huawei, the world's largest telecommunications manufacturer; Tencent, the most valuable Internet giant in China; DJI (i.e., Da Jiang), the cutting-edge drone manufacturer; Oppo, a leading consumer electronics company, and Ping An, the global insurance and fin-tech company. Among all those technology companies, Tencent is the most attractive employer among overseas returnees, Alibaba Group is the second, and Huawei is the fourth (Boss Career Science Lab, 2019). Located in Pearl River Delta, bordering Hong Kong, Shenzhen used to be a small agricultural and fishing village in Guangdong province in southern China. Since 1980, when the Open and Reform Policy was implemented, Shenzhen has grown into a thriving metropolitan city that dwarfs Hong Kong in technology and startups. It is a migrant city in China. Shenzhen's welcoming and tolerant city culture is its most attractive factor in attracting domestic Chinese talent. According to World Population Review (2020), the development and advancement of high-technology, financial services, and cultural industries all contributed to the population boom in Shenzhen since its establishment as China's first Special Economic Zone four decades ago. Shenzhen was voted as China's most dynamic city and the city most favored by migrant workers in 2014. It was selected as one of the top ten cities in China for expatriates (World Population Review, 2020). Expatriates choose it as a place to work and settle because of the job opportunities and the city's cultural tolerance and open-mindedness. UNESCO's Report on 10 Things to Know about Shenzhen (2009), named it as China's largest migrant city with the youngest population of an average age of 30.8. Most young migrants are well-educated, including one-sixth of China's doctoral degree recipients. Since 1980s, Shenzhen has cultivated a special city culture to welcome migrant workers and migrant professionals with different provincial and cultural backgrounds. Shenzhen's anti-establishment and welcoming culture contribute to its talent and migrants attraction, just as entrepreneurs and immigrants from across the globe were attracted to Silicon Valley. The China Urban Vitality Research Report (2017-2019) ${ }^{3}$ ranked Shenzhen as the top city in China in terms of its attractiveness (see Fig. 1). As shown in Fig. 1, Shenzhen ranked top 1 the most attractive city in China from 2017 to 2019, and its population attractiveness index has increased from 9.925 to 10.109 . Shenzhen has been surpassing traditionally known Chinese metropolitan cities like Guangzhou (ranked no. 2), Beijing, and Shanghai (ranked no. 4) as a career and residential destiny. In comparison, Beijing's attractiveness index decreased from 8.821 in 2018 to 8.816 in 2019.

This paper is devoted to a better understanding of talent migration during the international geo-political change. Positioned as China's Silicon Valley, Shenzhen local government has made great efforts to attract both domestic human capital and overseas returnees. China's President Xi Jinping announced a plan to implement pilot reforms in Shenzhen over the next 5 years at the 40th Anniversary Celebration

\footnotetext{
${ }^{3}$ China Urban Vitality Research Report has been released annually since 2017 by Baidu.
} 


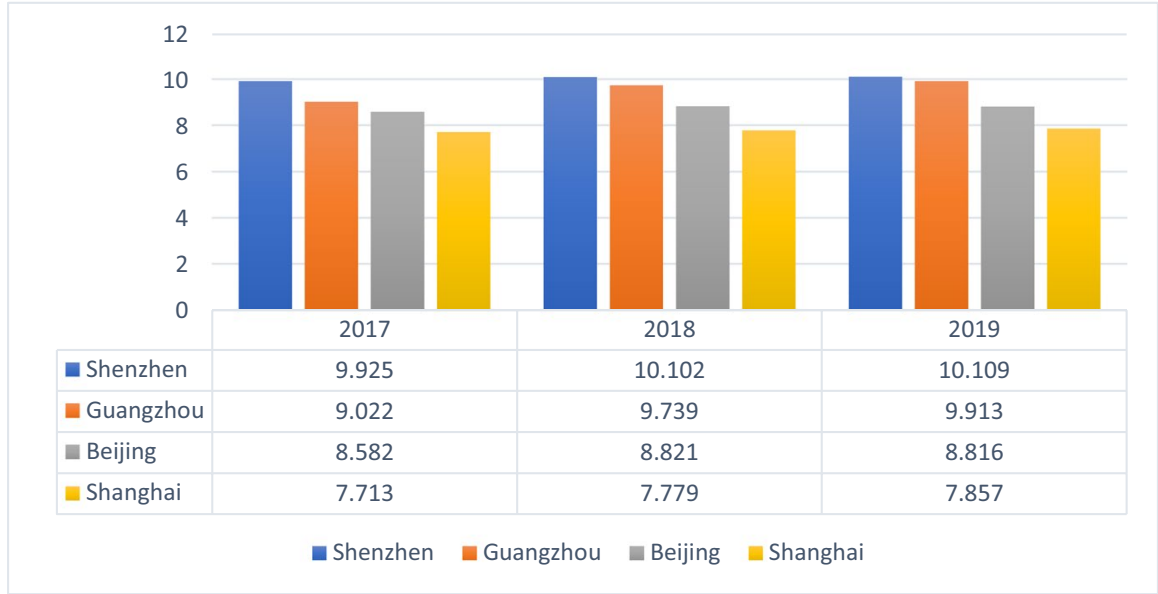

Fig. 1 2017-2019 Shenzhen, Guangzhou, Beijing, and Shanghai's city population attractiveness ranking

of Shenzhen Special Economic Zone in 2020. Shenzhen has undertaken the mission to advance its opening up in the new era and to build a pilot demonstration for other Chinese cities. ${ }^{4}$ Consistent with national goals, Shenzhen has developed its talent policy to advance the city's development by (1) attracting overseas returnees, (2) attracting foreign talent, (3) attracting domestic talent in science and engineering, and (4) improving Shenzhen's higher education. This study chooses Shenzhen as a case to examine China's global competition for talent in the race of global technological innovation. It mainly explores the effectiveness of local state's talent policy in brain circulation and how talent responds to Shenzhen talent policy. Different from more than a decade ago when city infrastructure was undertaken in major Chinese cities, does current brain circulation facilitated by city government policy and career opportunities contribute to brain circulation and brain gain to Shenzhen? This study analyzes domestic talent and overseas returnees' migration to Shenzhen, their demand for city environment, and their attitudes towards Shenzhen talent policy. Furthermore, talents' decisions in coming to Shenzhen or not coming to Shenzhen among different groups of population, in particular among transnational entrepreneurs, overseas academics, and young Chinese overseas students, are examined.

In addition, China is currently faced with two categories of overseas returnees: (1) old generation Chinese overseas students and (2) self-sponsored new generation overseas students whose education is paid for by well-off families. Some old generation overseas returnees are currently established scholars or successful business people who went abroad for study on Chinese government scholarships or university fellowships (some were sponsored by their families). The second kind is young generation Chinese who were born from the 1980s to the 1990s. They went to pursue

\footnotetext{
${ }^{4}$ Speech by Xi Jinping at the 40th Anniversary Celebration of Shenzhen Special Economic Zone in October, 2020.
} 
their studies overseas for college degrees or master's degrees whose tuition fees were paid for by their families. Question occurs in their returning decisions: Are there any differences between these categories in their decisions to return? Answers to the questions above are intended to contribute to migration literature on knowledge economy when talent rather than raw materials and resources is the economic driver. In addition, an examination of Shenzhen's talent policy opens new possibilities for international policymakers: Instead of placing restrictions on overseas Chinese talent to reduce technology transfer, drawing inspiration from Shenzhen's talent policy to advance their own national economy and innovation should be their priority. Also, the reform of higher education system is urgent, not only in China, but also worldwide. As analyzed in later section of this paper, overseas Chinese academics are reluctant to return to China for permanent faculty positions due to their fear of China's higher-education bureaucracy and the lack of freedom and dedicated time in conducting quality academic research. Findings revealed in this study on academics' attitude towards Shenzhen can be applicable to many cities, regions, and countries that aim to develop and transform their higher-education sector.

\section{Methodology}

This article is part of a research project on examining how and why Shenzhen has become China's Silicon Valley from historical, institutional, political, cultural, and social perspectives. For the longitudinal research project, I conducted semi-constructed in-depth interviews, running from 50 to $60 \mathrm{~min}$, with Shenzhen government officials, entrepreneurs, technology investors, university professors, and migrant workers and migrant professionals in Shenzhen. Questions on talent policy, the implementation, and the effectiveness of Shenzhen Peacock Talent program were constructed in the later stage of my research project, as Shenzhen Peacock Talent program and local government financial incentives were frequently mentioned by some interviewees, in particular by local government officials, entrepreneurs, and migrant talents (including both domestic migrants and overseas returnees).

For the original purpose of my longitudinal research project, I recruited interviewees and participants based on purposive sampling, followed by snowball sampling. Purposive sampling derives from my personal and professional networks in the following categories: local government officials, entrepreneurs, business leaders, makers, technology investors, university professors, and college students at Shenzhen local universities and colleges. The snowball sampling largely comes from my contacts' introduction as people in my personal and professional networks knew about my general research topic on Shenzhen and its technological innovation. Migrant workers, migrant white-collar professionals, and overseas returnees to Shenzhen are major targets in the snowball sampling process. Though Shenzhen is a migrant city and has many established local government officials and university professors, business leaders in Shenzhen were migrants in the early 1980s when Shenzhen was set as the first Special Economic Zone in China; most of the interviewees in this article, in particular overseas Chinese returnees and domestic migrant talent to Shenzhen, are relatively young, mostly ranging from 25 to 35 years old. 
I conducted most of the interviews in person, with some on Wechat ${ }^{5}$ due to COVID-19 pandemic shutdown since 2020. For overseas returnees to Shenzhen, in spite of their age, my interview questions focused on the reasons that they chose to come to Shenzhen, and whether or not Shenzhen Peacock Talent program has any influence on their decisions to work and live in Shenzhen. In addition, I asked financially self-sponsored overseas Chinese students on the comparisons between Shenzhen and their foreign host countries in terms of culture, careers, as well as personal and professional development. For Chinese domestic migrant professionals coming to Shenzhen, my questions emphasized on Shenzhen's city competitiveness compared to other metropolitan cities in China, such as Beijing, Shanghai, and Guangzhou.

In addition to semi-constructed in-depth interviews, secondary resources, such as government reports, documents, and archives are utilized to understand Shenzhen talent strategy and Shenzhen Peacock Talent program. Several surveys cited in this article were conducted by Shenzhen Social Science Committee, as their research efforts to understand Shenzhen talent demographics and the effectiveness of Shenzhen talent policy.

\section{Migration-Brain Drain, Brain Circulation}

Brain drain, as a form of migration, refers to talented young people moving from poor developing countries to advanced countries in the pursuit of education at universities, research, or work in areas where education and employment opportunities are limited in their home countries. Developing countries and regions, such as India, Taiwan, and mainland China worry about their brain drain and the consequential economic loss, as their human capital was the last resource they wanted to lose in a national competition (Saxenian, 2005; Todaro, 1985). Migration of skilled talent from developing countries to advanced countries during the late twentieth century has mainly involved migration from India and China to the USA. For instance, in 1998 to $1999,10.4 \%$ of international students enrolled in American universities were from mainland China (51,000 not including Hong Kong), and 7.6\% were from India (37,482) (Todd, 2000). Furthermore, between 1990 and 1996, 16,749 Chinese students and 8211 Indian students received their doctoral degrees in Science and Engineering from American universities (Johnson, 1998). With Silicon Valley's rapid growth in the technology sector from the 1970s through the 1990s, skilled technical immigrants from developing countries who came to the USA for Science and Engineering education found jobs in Silicon Valley. By 2000, 53\% of Silicon Valley's scientists and engineers were foreign born, with Indian and Chinese nationals accounting for over one quarter of the total personnel (estimate 20,000 Indians, 5000 Taiwan, and 1500 mainland China born) (Saxenian, 2005).

In contrast to brain drain, brain circulation happens when skilled overseas population return to their home countries after years of learning, living, and working

\footnotetext{
$\overline{5}$ Wechat, a popular social media messaging app.
} 
abroad. Some are called transnational entrepreneurs who return to home countries to start businesses through their established overseas business links. Transnational entrepreneurs spread international knowledge about the global markets while, at the same time, link economic opportunities between their home countries and host countries (Liu, 2017; Saxenian, 2005). Other returnees go back to teach at universities, while many work for multinational companies (Beaverstock, 2002; Cyranoski, 2002; Varshney, 2013; Zweig et al., 2004). Brain circulation, or brain gain, usually generates positive outcomes for their home countries because of the skills, capital, knowledge, or business connections the returnees bring back with them (Stark et al., 1998).

Literature on return migration has been discussed primarily on four theoretical models: the economic model, the structural approach, the transnational model, and the triangular model. The economic model emphasizes factors such as salary, living conditions, and family obligation (Guo \& DeVoretz, 2006; Todaro, 1969; Zweig \& Chen, 1995). Early generation Chinese doctoral degree recipients in Science and Engineering in the USA are an example of the economic framework (Zeithammer and Kellogg, 2013). Between 1988 and 1996, of 16,500 Chinese citizens who received doctoral degrees in Science and Engineering, 85\% planned to stay in the USA. Of those who planned to stay, half of them had firm offers, one-third had real jobs, and two-thirds held postdoctoral fellowships (Zweig et al., 2004). China's economic conditions at that time discouraged students from returning home. Due to economic gaps with the West, the material benefits for overseas returnees were incomparable to what they could obtain abroad (Chang \& Deng, 1992).

The structural approach attributed return migration to social and institutional factors in the country of origin (Li \& Lo, 2012). Research on China's brain drain focused on political hurdles proposition (Chang, 1992; Zweig \& Chen, 1995; Zweig et al., 2008; Simon \& Cao, 2009). Overseas Chinese students were reluctant to return to China especially after the 1989 Tiananmen incident, despite China's political leader, Deng Xiaoping's reassurances that despite those students' political attitude, all of them can return to China with no further punishment. Last, the transnational model (Andersson and Konrad, 2001; Ley \& Kobayashi, 2005) and the triangular model rationalized the move of immigrants with a focus on skilled talents, who are often temporary movers with a strategic plan (De Voretz et al., 2003; Guo \& DeVoretz, 2006; Zweig et al., 2008).

Factors that influence overseas talent's decision to return include political stability and sustained economic growth in home countries, change of political views and cultural values, homesickness and attachment to roots, racism and integration issues in host countries, tightening immigrant policies, and children's education (Zweig et al., 2004, 2008; Fu, 2014; Varshney, 2013). In the case of China's brain drain and brain gain, Chang and Deng (1992) revealed that Western influence has changed the social values of some overseas Chinese students. They embraced the value of individualism, and no longer put the state or national interests above their own pursuit of happiness and freedom. In the case of India, during the dotcom bubble period, some Indians who worked in information technology industry were forced to go back due to the economic slump and massive unemployment in the USA (Chacko, 2007). A recent study has shown that many Indians choose to return in recent years, as Indian 
higher education quality is increasing, providing more opportunities for returning talent's children in their home country. The internationally recognized Indian Institutes of Technology (IITs) and the Indian Institutes of Management (IIMs) offer a satisfying educational prospect to the children of those who wish to return to India. ${ }^{6}$

Brain circulation to China is not new, in particular to those people who wanted to seize the business opportunities and large Chinese markets to make their fortunes. Policymakers and representatives in China visited Silicon Valley repeatedly to recruit Chinese technical professionals to go back home. Most representatives came from Beijing and Shanghai. As Saxenian (1999) noted, Chinese cities such as Beijing established returning students venture parks exclusively designed for enterprises established or run by overseas returnees. The municipal governments offered infrastructure and financial benefits to address their needs, such as housing, tax benefits, and children's education. Beijing's Zhongguancun in Haidian district was known as a famous "returning students venture park." For instance, the founder of Baidu. com returned to Beijing and established Baidu.com in 2000 while his family stayed in Silicon Valley. Interestingly, by 2000, when representatives from Beijing flew to Silicon Valley to lure back talent to create "China's Silicon Valley," Shenzhen was transitioning from a labor-intensive export economy to "electronics-focused, and innovation-oriented" developmental direction led by the Shenzhen city government. As a new city in rapid catch-up mode, Shenzhen's talent policy is nothing new in terms of China's national initiative in attracting overseas returnees. However, it is different from Beijing or Shanghai's efforts in the early 1990s. Today, Shenzhen's robust Internet industries and other technological companies enable it to attract significant overseas talent.

Besides brain circulation who are transnational entrepreneurs, overseas Chinese scientific diaspora has been attracted to return to China in recent years. By the end of 2015 , over $79.9 \%$ of Chinese overseas students who completed their tertiary or post-graduate studies had returned to China. Among those returnees, many of them are doctoral degree holders who carry the mission to advance China's national scientific research and to turn China's leading universities into world-class level institutions (MOE, 2016; Zweig \& Wang, 2013).

This article is constructed in three major sections. The first following section analyzes Shenzhen's talent policy, Peacock Talent program, and the role central and city government play in attracting human capital as well as how domestic and foreign talents who were attracted to Shenzhen view the talent policy. The second part analyzes current brain circulation to China due to the international geopolitical chaos and its impact. The final section summarizes Shenzhen's current talent situation and offers concluding remark on policy implication which can be drawn from Shenzhen.

\footnotetext{
${ }^{6}$ Kelly Services Report: A World of Talent, 2010-2011. Retrieved from: https://www.kellyservices.com/ global/about-us/ir/financials--filings/annual-reports/
} 


\section{Shenzhen Talent Policy-Peacock Talent Program}

Shenzhen city government wants to attract talent to build and grow the city and develop cutting-edge technologies that are "Created and Made in China." Established in 2011, the Peacock Talent Policy is designed to attract talented overseas talent including both Chinese nationals and foreign citizens. Peacock Talent program is a high-level overseas talent initiative led by the municipal government to allure human capital who might help fulfill Shenzhen's fast changing developmental needs at the international level. According to its 2020 application requirements, their demand for talent falls into three categories. The first is A talent; superstars who received international awards, such as the Nobel Prize and Turing Award, are qualified to apply. Money incentives up to 3 million renminbi (in short, RMB, also called yuan, monetary unit of China) are available. Chief Executive Officers from fortune global 500 companies are also A talent, as are Olympic gold medalists. Their contribution to Shenzhen's technological innovation and development is that they serve as "city ambassadors." B and C level talents are more popular and reachable. For instance, anyone who served as a full or associate professor at world-renowned universities for more than 5 years qualify as a B talent, ${ }^{7}$ while assistant professors at the same level international universities can apply for $\mathrm{C}$ talent. The initial funding from the Peacock Talent program is 2 million $\mathrm{RMB}$ and 1.6 million $\mathrm{RMB}^{8}$ respectively. One research dean, Chinese ethnic heritage, at a collaborative international institution came to Shenzhen every summer for research and guided his students for 2 to 3 months. He spent the rest of his time in the USA. Despite the fame and international reputation of some research laboratory supervisors, young Chinese researchers and scientists receive limited guidance. Full-time local advisors are much more involved. The research dean acknowledged that some of his students chose to be at his laboratory, with the hope of transferring to his counterpart one in the USA eventually (Interview, 2019).

The reasons for Chinese returnee scientists not choosing to permanently relocate to Shenzhen vary. A study on the cultural analysis of academic returnees explained why some Chinese academics and scientists who held academic positions in Canada chose not to return to China. In Fu's (2014) research interview, one Chinese scientific professor did not believe that he could conduct quality research if he were in China. In his trip to Beijing, he observed the excess workloads and tight schedules of his Chinese counterparts. Busy with the hustle and bustle, he did not think it would be possible to conduct quality research and teaching since it takes time and a calm mind to focus on academic research (Fu, 2014). Meanwhile, some overseas Chinese academics held the view that Chinese guanxi culture has a tremendous influence on the attainment of research grants. Guanxi, in Chinese, 关系, similar to social capital in the Western context, usually refers to connections and relationship among people. However, in Chinese context, it often implies preferential treatment given to people

\footnotetext{
7 A, B, C talents here are referred as specific terms within Shenzhen Peacock Talent program.

82 million $\mathrm{RMB}=296,449.75$ USD, 1.6 million $\mathrm{RMB}=237,158.77 \mathrm{USD}$, in the currency exchange of 6.74 (as of October 12, 2020).
} 
in order to gain easy access to limited resources or opportunities (Lee et al., 2001). Thus, domestic Chinese academics focus more on maintaining social relationships to get promoted and to obtain grants. The prevalent guanxi culture in society and within China's scientific community makes it difficult for academics to advance based on fairness and equity. As Shi and Rao (2010) observed, in China's science academic community, connections with bureaucrats and powerful experts are critical and essential for career advancement.

Criticism of China's scientific education system and talent policy exists. Some Peacock Talents program opponents believe it is all about money. The city government attracts foreign talents and overseas returnees to create businesses in Shenzhen, with government subsidies. Some of them come and get the money without making contributions to local development (Interview, 2018). This phenomenon is not unique to Shenzhen. The city government attracts international talent to spur innovation in China's Silicon Valley. Top scientists and engineers are attracted to Shenzhen, or collaborate with local institutions on applied scientific innovations, not for basic scientific research. They are "scientific - entrepreneurs." Many of them hold foreign passports but are of Chinese descent. When they are back to Shenzhen, they work in large corporations as chief scientists, or they own technology firms. They serve as practical advisors at research institutions or universities, including institutions not located in Shenzhen. One chief scientist who came to Shenzhen under the "Thousand Talents" initiative said:

I feel very comfortable coming back (to China). I was born and grew up here until my doctoral pursuit in the U.S. I do not even have to adjust. I can get whatever I need here, at both the personal and professional level. (Interview, 2019)

This interviewed chief scientist has served as a practical advisor to one of the highest ranked science and engineering universities in northern China while also working as the chief scientist at a big company in Shenzhen. A 2013 Shenzhen Talent Research Report showed that the first two reasons that Peacock Talents ${ }^{10}$ chose to work and settled in Shenzhen were career interests (50\%) and societal acknowledgement (47.26\%). ${ }^{11}$ Peacock Talents who return to Shenzhen from overseas care most about their personal and professional satisfaction. They choose Shenzhen over other Chinese cities because Shenzhen can fulfill their ambitions to further their careers. A and B talents from overseas are already established leaders. They recognize what Shenzhen offers them and what it does not: well-developed manufacturing supply chains, rapid applied innovation, and supportive entrepreneurship policy, but not top-ranked research universities. Chinese news and government reports often note that Peacock Talents publish frequently in Nature and Science, but it is quite

\footnotetext{
9 Thousand Talents is not Shenzhen local talent program but a Chinese national one.

${ }^{10}$ In this manuscript, I used "Peacock Talents" as a term referring to talents attracted to Shenzhen under Shenzhen Peacock Talent initiative. I used "A Talent, B Talent, and C Talent" as terms referring to each talent category in Shenzhen Peacock Talent initiative.

11 Original report in Mandarin Chinese: 深圳人拓研究报告, Shenzhen Talent Research Report, 2013.
} 
possible that these people usually come for visits but do not stay in Shenzhen. They do not contribute to mentoring and educating the next generation of Chinese scientific researchers. Real scientific research exploration and its knowledge creation process come from the constant exchange of ideas, timely feedback, and repeated experiments. But young researchers require the adviser's or principal investigator's sustained guidance over time.

The education process in Shenzhen takes a much longer time, with limited immediate outcomes. One survey sponsored by the city government social science committee, Research on Shenzhen Talent Development Environment (2013), ${ }^{12}$ found that more than $60 \%$ of the survey participants thought Shenzhen's higher education system and academic environment was average or dissatisfying. Only $27 \%$ of the participants believed it was possible to enhance their academic career opportunities, while more than $60 \%$ of the participants complained that Shenzhen was an average or unpleasant place to pursue an academic career because academic and intellectual pursuits are hampered and academic exchange opportunities with foreign counterparts are limited. No specific reasons were provided for the lack of academic exchange opportunities in the survey though a local informant once commented implicitly that Shenzhen cannot surpass Beijing's role in all aspects. Shenzhen's lack of nurturing environment may be a key factor for its failing in building top-notched scientific institution and universities. Overseas returnees are not amazed by facilities such as spacious house but a healthy environment and a positive atmosphere to nurture their professional development (Ni, 2005). The absence of a nourishing academic environment in Shenzhen, or in China, makes some scientists keep their academic positions abroad in case of any unanticipated occurrences (Simon \& Cao, 2009).

One Peacock Talent drawback, survey participants in the report Research on Shenzhen Talent Development Environment noted, was the overemphasis on technical talents and high-level talent. The search for talent is a "demand-supply" way to meet current needs, not a long-term strategy or comprehensive local long-term talent cultivation. The same study found that $38.24 \%$ of the survey participants thought Shenzhen city government put too much emphasis on high-level talents and $13.26 \%$ agreed that the city government overemphasized attracting technical human capital. Predictably, Shenzhen city government and its district governments seek technical talents to fulfill their developmental needs. However, Shenzhen's competitors in technology sector are also trying to attract national and international talent and companies to enhance their regional developmental efforts. For instance, cities in Southwest China, such as Chongqing and Chengdu, are gaining recognition in their technology sector. Compared to Silicon Valley, Shenzhen has a smaller but growing talent pool. One program director at an international startup incubator viewed native Chinese engineers as good at mechanical engineering design but not at industrial design:

$\overline{12}$ This survey study is included in Shenzhen Talent Research Report, 2013. 
Table 12019 Top 15 most attractive employers among overseas returnees

\begin{tabular}{llll}
\hline 1 & Tencent & 9 & Ping An \\
2 & Alibaba Group & 10 & China Construction Bank \\
3 & Bank of China & 11 & Didi \\
4 & Huawei & 12 & Citic Securities \\
5 & XDF.cn & 13 & JD.com \\
6 & Netease & 14 & Bytedance \\
7 & Industrial and Commer- & 15 & Meituan \\
& cial Bank of China & & \\
8 & Baidu & & \\
\hline
\end{tabular}

Note: Source is Boss Career Science Lab.

Design is a form of art creation. The more you have seen, the more openminded you are, the more creative your designs are. Native Chinese are still lacking that training in their education. But the situation is getting better with more Haigui, or sea turtles (overseas students who return to China) with degrees and training in art and design. (Interview, 2019)

The interviewee observed that Huawei set its global aesthetic design center in Paris in 2015 for a reason. Huawei aims to enhance its interior and exterior product design, by building on Paris' longstanding tradition and reputation in art and design. Huawei's "seeking out" strategy reflects the talent shortage in the design field in Shenzhen. In spite of talent shortage in design, the 2020 Peacock Talent application instruction, set only one criterion, matches to the design talent demand needed to be B Talent award recipients of a product design award, German-based iF international industrial design award presented since 1954. It is extremely unlikely that an iF award winner would work at a local startup incubator to help unknown would-be technology entrepreneurs with their product design. City government is aware that some people under the city talent initiative take money with no concrete contributions in the implementation of Shenzhen Peacock Talent program. Some of the first batch of Peacock Talents were later disqualified due to their part-time positions. In addition, the average age of science academicians is 74 years old. More than 1500 of them hold 9000 part-time jobs but do not live in Shenzhen. Some local government officials seek reform of the program by restricting the location option to avoid the waste of funding and resources, in the hope of providing more concrete support to attract senior technicians and academics to Shenzhen. New overseas returnees, or new sea turtles (young generations of overseas Chinese students), are the proposed talent targets. ${ }^{13}$

\footnotetext{
${ }^{13}$ This information is found on Shenzhen High-tech talent committee website: http://www.gaoxinbutie. com/haiwairencai/
} 


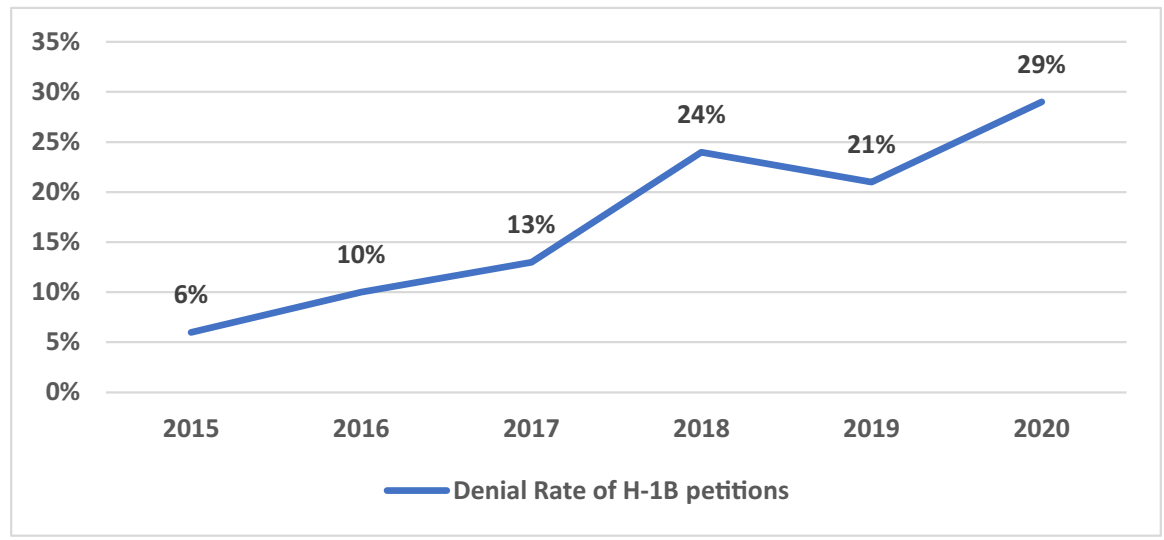

Fig. 2 Denial rate of H-1B petitions in the USA from 2015 to 2020. Note: Information is from U.S. Citizenship and Immigration Services Website. The 2020 figure is the rate at end of the second quarter of 2020

\section{Brain Circulation in a New Era}

In recent years, more Chinese nationals completing their studies overseas choose to return to China, and Shenzhen is one of their top destinies. Compared to other cities in China, Shenzhen particularly attracts knowledge workers in the Internet industry. Tencent, the Internet giant headquartered in Shenzhen, is the most attractive employer among overseas returnees. Alibaba Group, founded by Jack Ma, is second and Huawei is fourth. Bytedance, Tiktok's parent company, is fourteenth. Table 1 shows that the top 15 employers are all Chinese companies, many of them are technology enterprises which indicates the attractiveness of Chinese Internet companies among overseas Chinese student returnees. Chinese companies such as Tencent have offices in both Shenzhen and Beijing which provide returnees with the flexibility in choosing their preferred work location. One Tencent employee I had an interview with chose to work in Tencent Beijing office after her return from the UK because of her interest in Internet policy research. Tencent Shenzhen headquarter focuses on Internet product innovation and software development, while its Beijing office emphasizes on policy, intellectual property, and legal research, with the utilization of Shenzhen and Beijing's respective locational advantages.

Overseas Chinese students' increasing return is intertwined with uncertain geopolitical tensions China has faced overseas. As of October 2020, in the midst of COVID-19, about two-thirds of Chinese students who studied in the USA, UK, or Australia had returned to China. Three-fifths of them hold at least a master's degree (He, 2020). The online career development platform UniCareer found a 70\% increase from 2019 in terms of the number of overseas Chinese student returnees. The COVID-19 pandemic and tightening immigration and employment rules were the major reasons (He, 2020). For example, US Optional Practical Training (OPT), a post-graduation work permit that allows international students to legally work after they complete their studies was to be suspended by the Trump administration, 


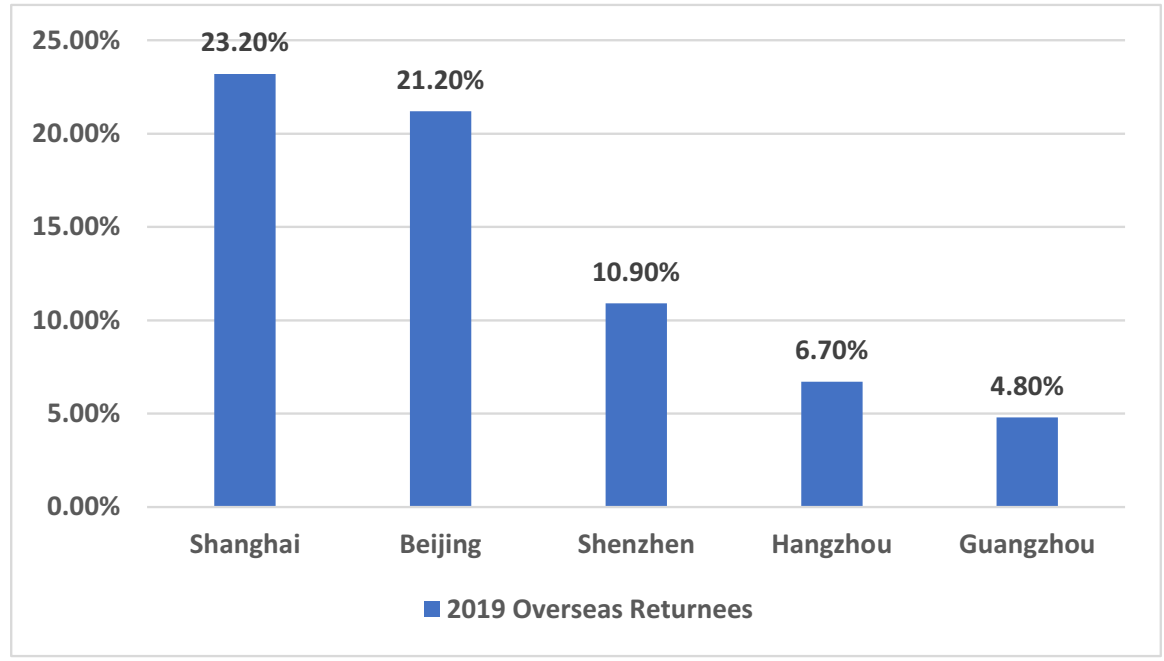

Fig. 32019 top five overseas returnees (Haigui) destination cities in China

threatening Chinese and other international communities. Some Chinese students, who are faced with the unpredictable circumstances, now depart for China immediately after their study. They do not want to miss the job recruitment cycle in China. Figure 2 shows that the denial rate of $\mathrm{H}-1 \mathrm{~B}$ visa petition increased from $6 \%$ in 2015 to $29 \%$ in 2020 . The H-1B program allows "companies in the United States to temporarily employ foreign workers in occupations that require the theoretical and practical application of a body of highly specialized knowledge and a bachelor's degree or higher in the specific specialty, or its equivalent." ${ }^{\text {"T }}$ The H-1B denial rate is an indicator of hardship that foreign nationals face if they seek further training or want to pursue careers in the USA at present.

As obtaining post-graduation work permits and H-1B work sponsorship becomes more difficult, the number of overseas Chinese students returning to China after graduation is increasing. "There are many more opportunities in China" is extremely popular sentiment among entrepreneurial overseas returnees. There are currently two categories of oversea returnees: one seeking work with employers in China, the other focusing on creating businesses in China built on their international visions and the advantage of massive Chinese market potentials. Ranked as the no. 3 overseas Chinese students' destination city (see Fig. 3), Shenzhen city government subsidizes returnee entrepreneurs with an amount of 500,000 RMB (74,117.30 USD), 250,000 RMB (37,058.65 USD), or 150,000 RMB (22,235.22 USD), based on their educational attainments and potential to welcome business creations and talent. Preferred industries for funding include information technologies, new materials engineering, new energies, biomedical engineering, advanced manufacturing and equipment, modern agriculture, clean-tech, and professional services such as

${ }_{14}$ Definition obtained from the official US Citizenship and Immigration Services Website. 
logistics. The startup funding that entrepreneurial overseas returnees receive is far less than the financial resources and housing awarded to Peacock Talent. One entrepreneur at a coworking space who attended high school in the UK and university in the USA stated, "Shenzhen government is very supportive. It is possible to use the government startup funding to purchase several office computers to get a company started" (Interview, 2019). Once considered as a "second rich generation," he seems to have reintegrated into a unique Chinese business environment, which requires him to play it well with the government by reenforcing the positive role government plays. Unlike overseas talent or transnational entrepreneurs lured back by the city government, he quit his job in finance in Shanghai before pursuing his entrepreneurial ambitions in Shenzhen. His major motivation for entrepreneurial pursuit was to make more money than what he got paid for working for others. Also, he wanted to prove to his parents that he could make his own fortune. In a follow-up phone interview, he expressed his frustrations on not knowing why American employers did not hire him: "Maybe because of language, cultural barriers, or unwillingness to sponsor foreigners. Who knows? No employer explained to me why they did not hire me" (Interview, 2020). His mention on the unwillingness to sponsor foreigners is worth pointing out as it is reported by several people that lack of sponsorship is the main barrier for foreigners to get a job in the USA (Interview, 2019).

Overseas returnee entrepreneurs, who hold advanced degrees such as $\mathrm{PhD}$, tell a different story. Founders from a medical data startup founded in Shenzhen in 2019 by three US overseas returnees are optimistic and positive about their startup's growth and development. "My other two co-founders are all male and received their $\mathrm{PhDs}$ in bio-medical engineering and statistics from renowned American universities. It is easy for them to get jobs in the United States in relevant industries. But, is it boring to just live a middle-class American life when you have the chance to be a first-mover startup founder in your field in China?" A female entrepreneur shared her entrepreneurial journey and enthusiasm with me, "In just two years, our startup has started to make promising revenues. We did not go through venture capital, instead, we simply applied 2 million RMB Peacock Talent government money to establish our company two years ago." However, it is not easy for all top-notched overseas returnees to achieve business success like they do. One key obstacle, some of them are faced with, is counter-cultural shock. The female entrepreneur further shared, "to be honest, some overseas returnees are too arrogant and proud of themselves. They consider themselves as elites who hold state-of-the-art technology, patent, and knowledge that they obtain from their $\mathrm{PhD}$ training. But, in Chinese business culture, most of the time, it is not necessarily your technology but your personality, your character, and your connections gain you the first business deal" (Interview, 2021).

Despite Shenzhen city government's efforts to attract overseas talent, many overseas Chinese students prefer Shanghai or Beijing. The lack of fine museums, theaters, or entertainment channels is one major complaint. Cultural facilities are a weak indicator in Shenzhen's overall city attractiveness. The city's percentage of "highly educated people among permanent residents" also counts as a disadvantage for returnees. Shenzhen college town (Xi Li College Town) is on the edge of the city and county areas. Some overseas returnees, who became professors in college 


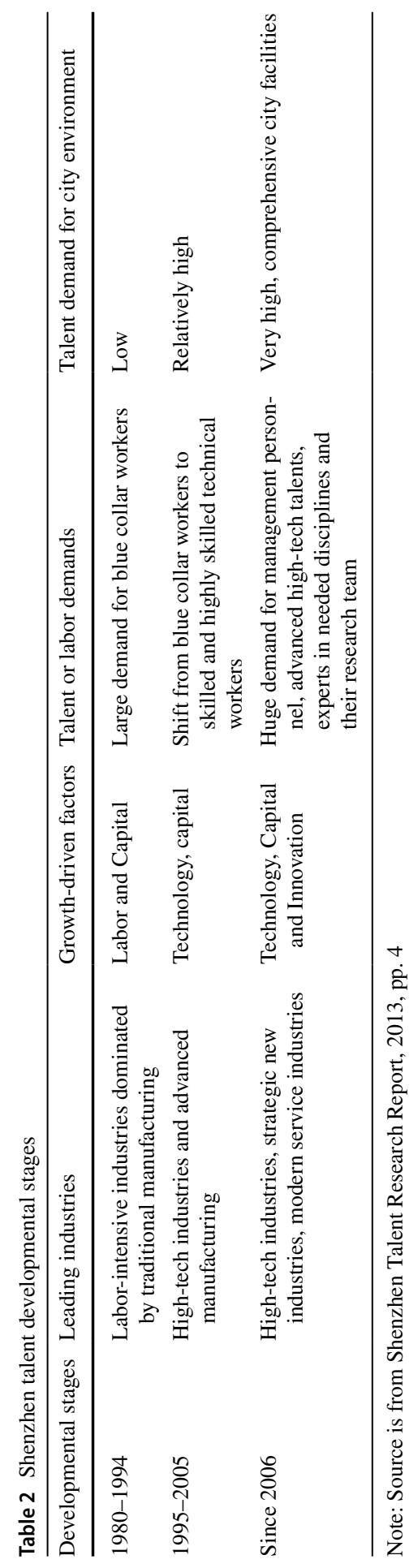




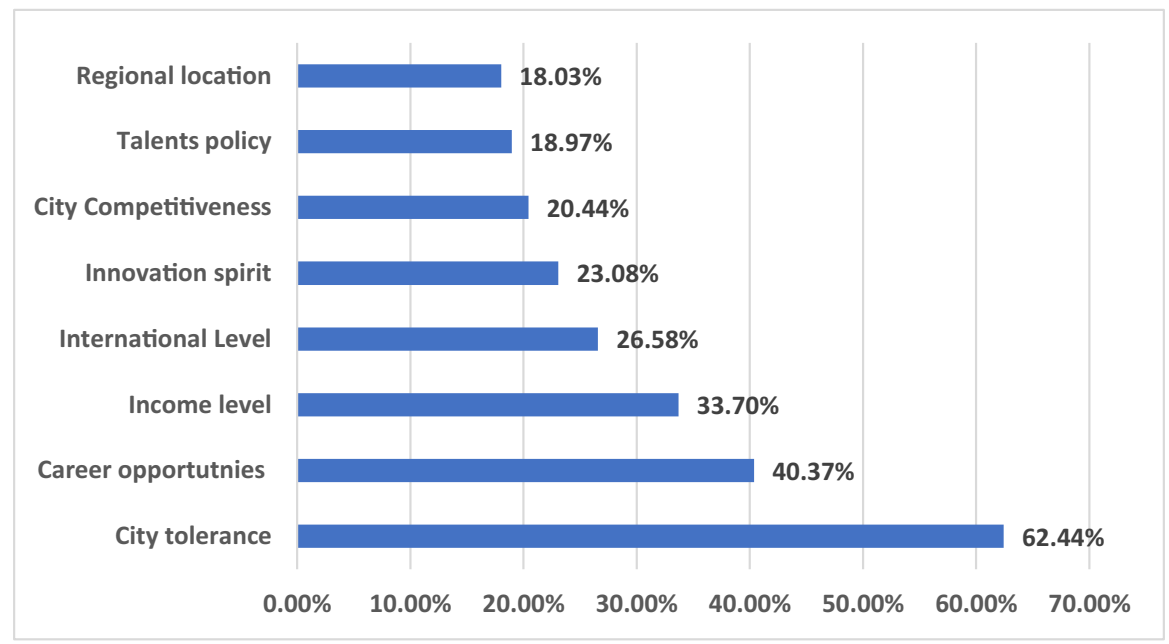

Fig. 4 Factors that attract talent to Shenzhen. Note: Information source is from Research on Shenzhen Talent Development Environment, pp. 69

town universities, complain that schools for their children are substandard. They want international level, not county level, schools for their children. Children's education has been a critical factor in overseas returnees' decision-making. The concern about the suffering of kids' education if relocated to China was expressed ( Fu, 2014). Complaints about both Shenzhen's lack of cultural opportunities and facilities that can entertain people with fine tastes and its shortage of top-flight schools indicate its current barriers to attracting international talent. Not surprisingly, two interviewees who are hardcore music fans often commute to nearby city Guangzhou for entertainment events. Table 2 demonstrates three major stages of Shenzhen talents and their demands for city environment. In the first stage from 1980 to 1994, Shenzhen's leading industry is traditional manufacturing and blue-collar workers are the major workforce. Their demand for city environment is low. With Shenzhen's technological development, since 2006, high-technology and service industries have become leading local industries which leads to local talents' demographic changes from blue-collars to advanced high-technology talents and research experts. Many of those talents have international education and living experiences which make their demand for city atmosphere and environment high: cultural facilities and entertainment amenities at the international level are desired.

Shenzhen has been catching up with its city infrastructure construction and entertainment amenities to be more international. In spite of its relative disadvantage, the key attraction of Shenzhen is its welcoming and tolerant culture. Survey participants in the study, Research on Shenzhen Talent Development Environment (2013), benefited from either the Peacock Talent Program or domestic talent initiatives. There was no way to tell the response differences in this data set between participants in the Peacock overseas talent and domestic talents policy programs. Among both overseas returning talent and domestic talent, $62.44 \%$ rated "Shenzhen city tolerance" as the 
top talent attraction factor. Career opportunities was listed second at $40.37 \%$. The talent policy ranks only the seventh (see Fig. 4).

Though there is no way of differentiating domestic talent from overseas returnee in the survey study above, however, some of my interviewees who were the target of domestic talent initiatives (they do not hold overseas degrees, though some may have overseas exchange study experience, and graduated from local Chinese universities) reported the significant role the talent policy played in their decisions in coming to work and live in Shenzhen. One male interviewee in his early 30 s said:

Among the first-tier cities in China, namely Beijing, Shanghai, Guangzhou, and Shenzhen, the welcoming and tolerant culture in Shenzhen is unbeatable. I happen to hold a doctoral degree that is in demand in the city. Therefore, I was assessed as "High-talented reserved talents," and I receive 320,000 RMB tax exempt from the city government every year. I am scheduled to receive this amount in maximum five years as a "reserved talent." (Interview, 2020)

As in the case of many other young migrant professionals, he also praised the timely professional information exchange in the fast-changing environment in Shenzhen. "I probably cannot even adjust to a slow pace work and lifestyle if I go to a third-tier city." More than Shenzhen's lifestyle keeps him in the city. He works at a technical company using his expertise and serves as an advisor to a local think tank, occasionally giving lectures on supply chain management. City dynamism and various job-hopping opportunities excite him. "I am just doing this for fun," was his catchphrase during our conversations, which suggested that he could change jobs easily in Shenzhen. He held a doctoral degree in new material engineering but acknowledged the "Shenzhen Talent Dilemma": No basic scientific research is conducted at local universities. Throughout my research interviews regarding talent migration to Shenzhen, it is clear that some renowned Chinese and foreign universities set up outposts in Shenzhen, but never bring their best professors in relevant disciplines there. Sometimes, students at Shenzhen campus need to commute to Beijing or other cities to meet with their advisors and research peers. Though there are not many renowned professors living and working permanently in Shenzhen, postdoctoral fellows are abundant there. The early $30 \mathrm{~s}$ male interviewee shared with me: "You know why there are so many postdoctoral fellows in Shenzhen? Because being a postdoctoral fellow increases your chances to secure national scientific research projects (to Shenzhen), so you would be qualified as a domestic high-talent in Shenzhen." Similar opinion was expressed by others: "to some extent, it is not Shenzhen's problem that it does not have advanced scientific research institutions or good comprehensive universities. National Ministry of Education assigns quotas to each university regarding the disciplines and subjects it allows to have." (Interview, 2019) The Shenzhen Talent Dilemma reflects its research and education drawbacks and highlights the dilemma of Shenzhen and China's higher education: Universities themselves lack autonomies in designing academic disciplines and creating new departments to recruit research talents. The evaluation of education and research accomplishments is assessed by the amount of grants and scientific research projects brought to Shenzhen but not the actual quality of research. Some doctoral degree holders in science and engineering apply for grants to achieve personal financial and 
talent-policy advancement to settle down in Shenzhen. The execution of local talent initiative is encouraged and supported by local government; however, higher education reform is controlled and limited by governments at higher levels. A professor from a renowned Chinese university commented on the stagnant progress of Southern University of Science and Technology established in Shenzhen in 2010:

The goal they set for Southern University of Science and Technology at that time was unreachable. It did not match with the overall social and political environment in China. The initial wish is good: Let intellectuals but not bureaucrats be in charge of the university. But, where does the university get funding from? They wanted to follow American style to organize a board and raise money from private enterprises or individuals. However, in the end, governments are back in charge. ${ }^{15}$ (Phone Interview, 2020)

\section{Conclusion}

Shenzhen's talent situation and the implementation of its existing talent policy reveal the effectiveness of its competition for talent. Shenzhen local government tries to achieve their developmental ends through the emphasis on a talent's specialization in their policy. The value of people's human capital is increased and valued if their expertise is in short supply in China. City government will make sure talent in Shenzhen is valued above regular market rates to keep them there. This kind of state policy interference is not new in China's talent policy: A state that is undergoing an economic transition rewards skilled talent who can facilitate those changes (Zweig et al., 2004). Some of those highly valued human capital are overseas returnees. This study uncovers that, different from Chinese overseas returnees a decade ago who returned for patriotic reasons and economic benefits, younger generation talent cares more about a city's cultural and entertainment facilities. "Where can I go for fun?" was frequently mentioned in my interviews. Also, talent in Shenzhen benefits from the dynamism in the city; timely and efficient information exchange helps them look for the "next, best opportunity." As revealed in the survey results, it is not surprising that "city tolerance level" was ranked top reason in talent's decision-making. The top ranking of Shenzhen's welcoming culture and city tolerance implicitly demonstrated a cultural change in Chinese society: Younger generations, both domestic talent and overseas returnees, differ from older generations in that they are more individualistic and care a lot about their personal contentment and happiness rather than merely economic benefits. Also, young generation Chinese who care about their career advancement value mentorship in cities or at companies where they work.

Shenzhen, as China's Silicon Valley, enjoys a unique advantage in attracting both overseas returnees and domestic talent, which are its mature manufacturing supply

\footnotetext{
${ }^{15}$ In 2013, a Communist Party Division was established at Southern University of Science and Technology.
} 
chain and the ability to commercialize innovation ideas to products at a fast rate. Scientists and engineers who long for opportunities to develop their laboratory ideas to markets to reap economic rewards value Shenzhen. However, as Shenzhen's past stories show, "scientific-entrepreneurs" do not conduct scientific research or mentor next generation Chinese researchers once they are in Shenzhen. They are clear about their reasons being in Shenzhen and focusing on their goals. Most of them are already established. These people do not need a nurturing academic environment or mentorship, which is a key disadvantage of Shenzhen shown in the survey result and the interviews. It is necessary that Shenzhen realizes its fundamental difference from Silicon Valley: Dedicated academics and intellectuals who devote themselves to education and research (in both science and social science) is a critical foundation to technological advancement and quality higher education which cannot be achieved simply by state monetary incentives and housing benefits. Intellectuals and academics care about the synergetic and open academic environment that gives them freedom to pursue knowledge. Also, they want to have people of the same caliber with whom they can discuss and debate ideas. In other words, the reform of higher education system is necessary to attract academics who are passionate about science and research and not merely motivated by money incentives.

In terms of host countries' and home countries' entrepreneurship relationship, interviewees who completed their bachelor and master degrees in the East Coast of the USA expressed that their counterparts in the West Coast seemed to get involved with entrepreneurship more than they did during their study period in the USA and there were more innovation-related forums and conferences in the West Coast, in particular in California, that can help overseas Chinese students build their business and entrepreneurial networks.

A welcoming and tolerant city culture remains a key attractor in Shenzhen. City slogan, like "You are a Shenzhener once you come to Shenzhen," demonstrates its migrant city attitude. An open and welcoming culture is important in any city, region, and country which hopes to attract talent, and most importantly, retain talent. Personal wellbeing and happiness, along with career satisfaction, are all associated with tolerance. Shenzhen's migrant history and welcoming culture are unique in Chinese society: People tend to believe they are evaluated and judged by their accomplishment but not by their families" "guanxi" or their "hukou" (residential permit, referring to where they were born). Less restriction on "hukou" is particularly significant in a sense that "hukou" system created in mainland China in the late 1950 s was initially meant to restrict rural-urban internal migration and to preserve social mobility. Hukou system still remains as a barrier for social stability and protection in some Chinese cities where it is hard for migrant workers and migrant professionals to obtain legal status to further gain access to public resources, for instance, good-ranking public schools. The migrant city spirit in Shenzhen plays a positive role in motivating people to fight for their own happiness and fortune. It is critical for Shenzhen to maintain this open city culture in its next developmental stage. Shenzhen's advantage in attracting talent highlights the significance of tolerance in human capital mobility which is extremely important in today's international competition: A country would probably lose not only its foreign talent, but also its own national talent, if the social, cultural, and academic environment is hostile while 
political instability is increasing. Increasing cultural and social tolerance is critical to attract and retain talent.

\section{References}

Andersson, F., \& Konrad, K. A. (2001, January). Globalization and human capital formation. Center for Economic Policy Research. Discussion Paper No. 2657. Retrieved October 13, 2020, from https:// www.ssrn.com/abstract $=265622$

Bartel, A. P., \& Lichtenberg, F. R. (1988). Technical change, learning, and wages (No. 2732). National Bureau of Economic Research. Retrieved October 13, 2020, https://www.nber.org/papers/w2732.pdf

Beaverstock, J. V. (2002). Transnational elites in global cities: British expatriates in Singapore's financial district. Geoforum, 33(4), 525-538.

Boss Career Science Lab. (2019). Overseas returning Chinese students employment trend. Retrieved April 9, 2019, from https://www.199it.com/archives/859350.html

Castells, M. (2000). The rise of the network society. (2nd ed., Vol. 1). The Information Age: Economy, society and culture. Wiley-Blackwell. (Original work published 1996).

Chacko, E. (2007). From brain drain to brain gain: Reverse migration to Bangalore and Hyderabad. India's Globalizing High Tech Cities. Geojournal, 68(2-3), 131-140.

Chang, P., \& Deng, Z. (1992). The Chinese brain drain and policy options. Studies in Comparative International Development, 27(1), 44-60.

Chang, S. L. (1992). Causes of brain drain and solutions: The Taiwan experience. Studies in Comparative International Development, 27(1), 27-43.

Cyranoski, D. (2002). Plugging the Brain Drain. Nature, 417(6890), 683. https://doi.org/10.1038/417683a

De Voretz, D. J., Ma, J., \& Zhang, K. (2003). Triangular human capital flows: Some empirical evidence from Hong Kong and Canada. In J. G. Reitz (Ed.), Host societies and the reception of immigrants (pp. 469-492). Center for Comparative Immigration Studies.

Florida, R. (1999). The role of the university: Leveraging talent, not technology. Issues in Science and Technology, 15(4), 67-73.

Fu, M. (2014). A cultural analysis of China's scientific brain drain: The case of Chinese immigrant scientists in Canadian academia. Journal of International Migration and Integration, 15(2), 197-215.

Guo, S., \& DeVoretz, D. J. (2006). The changing face of Chinese immigrants in Canada. Journal of International Migration and Integration, 7(3), 275-300. https://doi.org/10.1007/s12134-006-1014-0

He, H. F. (2020, September 21). China's overseas graduates return in record numbers into already crowded domestic job market. South Morning China Post. Retrieved September 30, 2020, from https://www.scmp.com/economy/china-economy/article/3102384/chinas-overseas-graduatesreturnrecord-numbers-already

Johnson, J. M. (1998). Statistical profiles of foreign doctoral recipients in science and engineering: Plans to stay in the United States. National Science Foundation, Division of Science Resources Studies, NSF 99-304. Retrieved August 15, 2020, from https://www.files.eric.ed.gov/fulltext/ED427948.pdf

Lee, D. J., Pae, J. H., \& Wong, Y. H. (2001). A model of close business relationships in China (guanxi). European Journal of Marketing, 35(1/2), 51-69. https://doi.org/10.1108/03090560110363346

Ley, D., \& Kobayashi, A. (2005). Back to Hong Kong: Return migration or transnational sojourn? Global Networks, 5(2), 111-127.

Li, W., \& Lo, L. (2012). New geographies of migration?: A Canada-US comparison of highly skilled Chinese and Indian migration. Journal of Asian American Studies, 15(1), 1-34.

Liu, Y. (2017). Born global firms' growth and collaborative entry mode: The role of transnational entrepreneurs. International Marketing Review., 34(1), 46-67.

Ministry of Education of the People's Republic of China (MOE) (2016). Profile of overseas Chinese students in 2015. Retrieved August 15, 2020, from https://www.moe.edu.cn/jyb_xwfb/gzdt_gzdt/ s5987/201603/t20160316_233837.html

Ni, Z. (2005). Simple analysis of Haigui phenomenon. Economic and Social Development, 6, 78-80.

Romer, P. M. (1990). Endogenous technological change. Journal of political Economy, 98(5, Part 2), 71-102.

Saxenian, A. (1999). Silicon Valley's New Immigrant Entrepreneurs. Public Policy Institute of California. 
Saxenian, A. (2005). From brain drain to brain circulation: Transnational communities and regional upgrading in India and China. Studies in Comparative International Development, 40(2), 35-61.

Schumpeter, J. (1942). Capitalism, socialism and democracy. Harper Torchbooks.

Shi, Y., \& Rao, Y. (2010). China's research culture [Editorial]. Science, 329(5996), 1128. https://doi.org/ $10.1126 /$ science. 1196916

Simon, D. F., \& Cao, C. (2009). China's emerging technological edge: Assessing the role of high-end talent. Cambridge University Press. https://doi.org/10.1017/CBO9780511803468

Stark, O., Helmenstein, C., \& Prskawetz, A. (1998). Human capital depletion, human capital formation, and migration: A blessing or a "curse"? Economics Letters, 60(3), 363-367

Tian, F. M. (2016). Brain circulation, diaspora and scientific progress: A study of the international migration of Chinese scientists, 1998-2006. Asian and Pacific Migration Journal., 25(3), 296-319. https://doi.org/10.1177/0117196816656637

Todaro, M. P. (1969). A model of labor migration and urban unemployment in less developed countries. The American Economic Review, 59(1), 138-148.

Todaro, M. E. (1985). Economic development in the third world. Longman.

Todd, M. D. (2000). Open Doors: Report on international educational exchange. Institute of International Education, New York. Retrieved July 29, 2020, from https:/www.files.eric.ed.gov/fulltext/ ED448658.pdf

UNESCO City of Design. (2009). Ten things to know about Shenzhen. Retrieved December 14, 2019, from https://www.unesdoc.unesco.org/ark:/48223/pf0000184151

Varshney, D. (2013). The Return of the natives: Asian diaspora issues and dilemmas, the case of India. African and Asian Studies, 12(3), 290-321.

World Population Review. (2020). Shenzhen. Retrieved August 10, 2020, from https://www.worldpopul ationreview.com/world-cities/shenzhen-population

Wübbeke, J., Meissner, M., Zenglein, M. J., Ives, J., \& Conard, B. (2016). Made in China 2025: The making of a high-tech superpower and consequences for industrial countries. Mercator Institute for China Studies. Retrieved from July 1, 2020, from https://www.merics.org/en/paperson-china/ made-china-2025

Zeithammer, R., \& Kellogg, R. (2013). The Hesitant "Hai Gui": Return migration preferences of U.S.Educated Chinese scientists and engineers. Journal of Marketing Research, 50(5), 644-663.

Zweig, D., \& Chen, C. G. (1995). China's brain drain to the US: Views of overseas Chinese students and scholars in the 1990s. University of California, Berkeley.

Zweig, D., \& Wang, H. (2013). Can China bring back the best? The Communist Party organizes China's search for talent. The China Quarterly, 215, 590-615

Zweig, D., Changgui, C., \& Rosen, S. (2004). Globalization and transnational human capital: Overseas and returnee scholars to China. The China Quarterly, 179, 735-757. https://doi.org/10.1017/S0305 741004000566

Zweig, D., Fung, C. S., \& Han, D. (2008). Redefining the brain drain: China's 'diaspora option'. Science, Technology and Society, 13(1), 1-33

Zwetsloot., R. (2020). China's approach to tech talent competition: Policies, results, and the developing global response. Brookings Institute. Retrieved June 11, 2020, from https://www.brookings.edu/wpcontent/uploads/2020/04/FP_20200427_china_talent_policy_zwetsloot.pdf

Publisher's Note Springer Nature remains neutral with regard to jurisdictional claims in published maps and institutional affiliations. 